\title{
Serum 25-hydroxy vitamin D, vitamin B12 and folic acid levels in myasthenic crisis
}

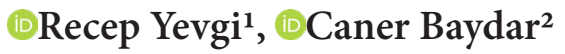 \\ ${ }^{1}$ Atatürk University, Faculty of Medicine, Department of Neurology, Erzurum, Turkey \\ ${ }^{2}$ Yüzüncü Yll University, Faculty of Medicine, Department of Neurology, Van, Turkey
}

Cite this article as: Yevgi R, Baydar C. Serum 25-hydroxy vitamin D, vitamin B12 and folic acid levels in myasthenic crisis. Anatolian Curr Med J 2022; 4(1); 29-33.

\begin{abstract}
Aim: Myasthenia gravis (MG) is an autoimmune disease often caused by autoantibodies against postsynaptic acetylcholine receptors (AChR). It is known that vitamin D (VD), vitamin B12 and folic acid have some effects on the immune system. The aim of this study is to evaluate whether there is a difference in serum VD, vitamin B12 and folic acid levels in MG patients during the myasthenic crisis period compared to the non-crisis period.

Material and Method: 32 patients followed up with the diagnosis of MG in Atatürk University Faculty of Medicine, Department of Neurology were included in the study. Serum 25(OH)D, vitamin B12 and folic acid levels were measured by taking blood from the antecubital vein in two different time periods, during the myasthenic crisis and during the non-crisis period, and periods were compared among themselves.

Results: During the myasthenic crisis period, 25(OH)D level was 11.54 (1.08-50.33) ng/mL, vitamin B12 level was 299.5 (104964) $\mathrm{pg} / \mathrm{mL}$, and folic acid level was $9.54 \pm 5.08 \mathrm{ng} / \mathrm{mL}$. In the non-crisis period, 25(OH)D level was 18.74 (6.63-30.19) ng/ $\mathrm{mL}$, vitamin B12 level was 266 (119-678) pg/mL and folic acid level is $10.26 \pm 3.5 \mathrm{ng} / \mathrm{mL}$. During the myasthenic crisis period, $25(\mathrm{OH}) \mathrm{D}$ vitamin levels of the patients were statistically significantly lower than the non-crisis period $(\mathrm{p}<0.05)$. There was no difference between the two periods in terms of vitamin B12 and folic acid ( $\mathrm{p}>0.05)$.

Conclusion: Low VD levels can be a facilitating factor in worsening myasthenic symptoms and entering myasthenic crisis. The use of VD supplements in MG patients with low VD levels may be beneficial in terms of protection from myasthenic crisis. Despite the limitations of our study, such as the small number of patients and the fact that $25(\mathrm{OH}) \mathrm{D}$ levels were not adjusted for seasonal effects, this study is the first study showing that VD levels are lower in the myasthenic crisis period than in the non-crisis period.
\end{abstract}

Keywords: Myasthenia gravis, myasthenic crisis, 25-hydroxy vitamin D, vitamin B12, folic acid

\section{INTRODUCTION}

Myasthenia gravis (MG) is a chronic autoimmune disease caused by autoantibodies that develop against postsynaptic acetylcholine receptors (AChR) frequently at the neuromuscular junction. Most commonly, antiAChR and anti-muscle specific tyrosine kinase (MuSK) antibodies are positive. Various degrees of muscle weakness that occurs and fluctuates in the ocular, bulbar muscles and extremity and respiratory muscles is the most important clinical feature of the disease. Myasthenic crisis can be defined as a life-threatening worsening of symptoms such as dysphagia and respiratory distress in MG. Myasthenic crisis may occur in some patients as the first manifestation of MG. The risk of myasthenic crisis is high in the first years of the disease. The risk of myasthenic crisis in patients with MG is 2-3\% per year (1). Conditions such as the use of certain drugs, infection, pregnancy, surgical operation, physical stress, discontinuation of immunosuppressive drugs or reducing their dose may cause myasthenic crisis in MG patients.

Vitamin D (VD) is a steroid hormone with a cytosolic receptor. The main function of $\mathrm{VD}$ is to regulate calcium homeostasis and bone formation via the parathyroid glands, kidneys and intestine. Besides these critical functions in calcium metabolism, it has been shown to play a role in the modulation of the immune system (2). 25 -hydroxyvitamin D $(25(\mathrm{OH}) \mathrm{D})$ is the most commonly 
measured circulating form of VD (3). The half-life of $25(\mathrm{OH}) \mathrm{D}$ is $14-21$ days and it is a marker which reflects the body's VD levels and reserves. 25(OH)D level above $30 \mathrm{ng} / \mathrm{mL}$ is considered normal, between 20-30 ng/ $\mathrm{mL}$ is considered insufficient, and below $20 \mathrm{ng} / \mathrm{mL}$ is considered as deficiency (4).

On the other hand, B group vitamins mainly serve as cofactors of enzymes involved in energy metabolism and the synthesis of organic molecules. Thanks to these functions, they play an significant role in the immune system, which consists of cells with high turnover. This is especially true for folic acid and vitamin B12, which have some functions in the nucleotide synthesis of proteins and deoxyribonucleic acid (DNA) $(5,6)$.

Folic acid and vitamin B12 metabolism are closely related as methylcobalamin is required for the regeneration of tetrahydrofolate. Folic acid has been reported to be effective on some immune system functions (6-8).

The number of studies on vitamin levels in MG is limited. According to our research, there are no studies on $\mathrm{VD}$, vitamin $\mathrm{B} 12$ and folic acid levels which have some effects on the immune system during myasthenic crisis. Our aim in this study is to evaluate whether there is a difference in serum VD, vitamin B12 and folic acid levels of MG patients during the myasthenic crisis period compared to the non-crisis period, and to evaluate the effect of this situation on the myasthenic crisis as a trigger.

\section{MATERIAL AND METHOD}

The study was carried out with the permission of Ethics Board of Atatürk University, Faculty of Medicine (Date: 06/33, Decision No: 30.09.2021). All procedures were carried out in accordance with the ethical rules and the principles of the Declaration of Helsinki.

Forty patients followed up with the diagnosis of MG in the Neurology Department of Atatürk University Faculty of Medicine were included in the study. Those younger than 18 years of age, pregnant, using corticosteroids, ocular MG patients, and using VD, vitamin B12 and folic acid supplements were excluded from the study. 3 patients were excluded from the study at their own request, due to pregnancy in 1 patient, and 4 patients using vitamin $\mathrm{D}$, vitamin $\mathrm{B} 12$ or folic acid. The study was continued with $32 \mathrm{MG}$ patients. Based on the presence of MG clinical features and neurological examination findings, detection of elevated levels of antibodies (anti-AChR or anti-MuSK antibodies), and/or electrophysiological studies ( $\geq 10 \%$ decremental response on repetitive nerve stimulation or increased jitter on single fiber electromyography), patients are given MG diagnosis was made. AntiAChR and anti-MuSK antibody tests were performed by enzyme-linked immunoassay method. Myasthenic crisis was defined as the life-threatening worsening of myasthenic symptoms such as dysphagia and dyspnea and the need for intravenous immune globulin (IVIG), plasmapheresis or mechanical ventilation due to this worsening.

Blood was taken from the antecubital vein from the patients during two different periods which are during the myasthenic crisis and the non-crisis period. All samples were collected at 9:00 am after 12 hours of fasting. Standart straight biochemistry tubes were used to collect blood samples. After waiting for half an hour, the blood samples were centrifuged at $5000 \mathrm{rpm}$ for five minutes and serum samples were obtained. Serum samples were placed in Eppendorf tubes and stored at $-80^{\circ} \mathrm{C}$ until analysis of VD, vitamin B12 and folic acid levels. 25(OH) $\mathrm{D}$, vitamin B12 and folic acid levels were measured by chemiluminescence method in Beckman Coulter UniCel Dxl 800 brand device.

Normal range of $25(\mathrm{OH}) \mathrm{D}$ level was $25-80 \mathrm{ng} / \mathrm{mL}$, normal range for vitamin B12 level was 126.5-505 pg/ $\mathrm{mL}$ and normal range for folic acid level was 3.1-19.9 $\mathrm{ng} / \mathrm{mL}$.

Body mass index was calculated by dividing the patient's body weight in kilograms by the square of the patient's height in meters $\left(\mathrm{kg} / \mathrm{m}^{2}\right)$.

\section{Statistical Analysis}

Summary statistics of all participants were obtained based on the means and standard deviations for normally distributed data and, medians and min-max for non-normal distributed data. The distribution of normality was assessed with the D'Agostino-Pearson test. Continuous variables with normal distribution belonging to two groups were compared using the student t-test whereas non-normal distributed data were compared using the Wilcoxon test. A two-tailed p-value $<0,05$ was considered statistically significant. All statistical analyzes were performed using Statistical Package for the Social Sciences (SPSS 20.0).

\section{RESULTS}

Thirty two MG patients were included in the study. Sixteen of the patients were male and 16 were female. The mean age of female patients was $43.3 \pm 16.8$, and the mean age of male patients was $46.1 \pm 17.1$. Anti-AChR antibody in 31 patients and anti-MuSK antibody in 1 patient were positive. Detailed clinical and demographic characteristics of the patients are given in Table $\mathbf{1}$. 


\begin{tabular}{|c|c|}
\hline Features & Number $(n=32)$ \\
\hline \multicolumn{2}{|l|}{ Gender (n,\%) } \\
\hline Woman & $16(50)$ \\
\hline Man & $16(50)$ \\
\hline \multicolumn{2}{|l|}{ Age $($ median \pm SD) } \\
\hline Woman & $44.3 \pm 14.8$ \\
\hline Man & $46.1 \pm 15.4$ \\
\hline Disease Duration (years) & $6.2 \pm 2.7$ \\
\hline \multicolumn{2}{|l|}{ Antibody (n,\%) } \\
\hline Anti-AChR Positive & $30(93.8)$ \\
\hline Anti-MuSK Positive & $2(6.2)$ \\
\hline \multicolumn{2}{|l|}{ Treatment $(\mathrm{n}, \%)$} \\
\hline Pyridostigmine & $3(9.3)$ \\
\hline Pyridostigmine, Mycophenolate mofetil & $5(15.6)$ \\
\hline Pyridostigmine, Azathioprine & $17(53.1)$ \\
\hline Rituximab & $2(6.2)$ \\
\hline Monthly IVIG & $5(15.6)$ \\
\hline \multicolumn{2}{|l|}{ Body mass index $\left(\mathrm{kg} / \mathrm{m}^{2}\right)($ median $\pm \mathrm{SD})$} \\
\hline Man & $26.03 \pm 2.2$ \\
\hline Woman & $25.11 \pm 4.1$ \\
\hline
\end{tabular}

25(OH)D level was determined as $11.54(1.08-50.33)$ $\mathrm{ng} / \mathrm{mL}$ during the myasthenic crisis period and as $18.74(6.63-30.19) \mathrm{ng} / \mathrm{mL}$ in the non-crisis period (Table 2, Figure 1a). During the myasthenic crisis period, 25(OH)D vitamin levels of the patients were statistically significantly lower than the non-crisis period $(\mathrm{p}<0.05)$.

Vitamin B12 level was found to be 299.5 (104-964) $\mathrm{pg} / \mathrm{mL}$ in the myasthenic crisis period and 265 (119678) $\mathrm{pg} / \mathrm{mL}$ in the non-crisis period (Table 2, Figure 1b). No significant difference was observed between vitamin B12 levels in myasthenic crisis and non-crisis periods $(\mathrm{p}>0.05)$.

Folic acid level was found to be $9.54 \pm 5.08 \mathrm{ng} / \mathrm{mL}$ during the myasthenic crisis period and $10.26 \pm 3.5 \mathrm{ng} /$ $\mathrm{mL}$ during the non-crisis period (Table 2, Figure 1c). In our study, no significant difference was observed in folic acid levels of MG patients in the crisis and noncrisis periods $(\mathrm{p}>0.05)$.
Table 2. Serum vitamin D, vitamin B12, folic acid levels of patients during myasthenic crisis and non-crisis periods

\begin{tabular}{|lccc|}
\hline Level & $\begin{array}{c}\text { Myasthenic } \\
\text { Crisis Period }\end{array}$ & $\begin{array}{c}\text { Non-Crisis } \\
\text { Period }\end{array}$ & P \\
\hline 25(OH)D ( ng/mL) & $\begin{array}{c}11.54 \\
(1.08-50.33)\end{array}$ & $\begin{array}{c}18.74 \\
(6.63-30.19)\end{array}$ & $0.01^{*}$ \\
Vitamin B12 ( pg/mL) & $\begin{array}{c}299.5 \\
(104-964)\end{array}$ & $\begin{array}{c}266 \\
(119-678)\end{array}$ & 0.15 \\
Folic acid $(\mathrm{ng} / \mathrm{mL})$ & $9.54 \pm 5.08$ & $10.26 \pm 3.5$ & 0.54 \\
\hline $\begin{array}{l}\text { 25(OH)D: 25-hydroxy vitamin D, }{ }^{*} \text { Statistical significance level according to Wilcoxon } \\
\text { test }\end{array}$
\end{tabular}

\section{DISCUSSION}

Aricha et al. (9) showed in their study which is performed with mice with experimental autoimmune myasthenia gravis disease that peripherally circulating regulatory $\mathrm{T}$ cells (Treg) control self-reactive $\mathrm{T}$ cells, leading to inhibition of the autoimmune response and play an important role in the disease process.

It is known that VD directly inhibits effector $\mathrm{T}$ cells and induces Treg cells to reduce the production of inflammatory cytokines. Low levels of VD have been demonstrated in some autoimmune diseases, including systemic lupus erythematosus (SLE), rheumatoid arthritis and multiple sclerosis attacks (10-12). Low 25( $\mathrm{OH}) \mathrm{D}$ levels have been found in coronavirus disease (COVID-19) patients and it is stated that this may be associated with musculoskeletal symptoms that may occur in COVID-19 (13).

Likewise, it has been shown that VD levels are lower in MG patients than in healthy individuals and that VD supplementation in MG patients has beneficial effects on fatigue scores (14-16). However, these studies do not reflect the myasthenic crisis period.

In our study, 25(OH) vitamin D levels of the patients were found to be lower in the myasthenic crisis period compared to the non-crisis period. The fact that VD levels are lower in MG patients compared to healthy controls and that they are found to be lower in the myasthenic crisis period than in the non-crisis period may indicate that low VD levels may be an important factor in

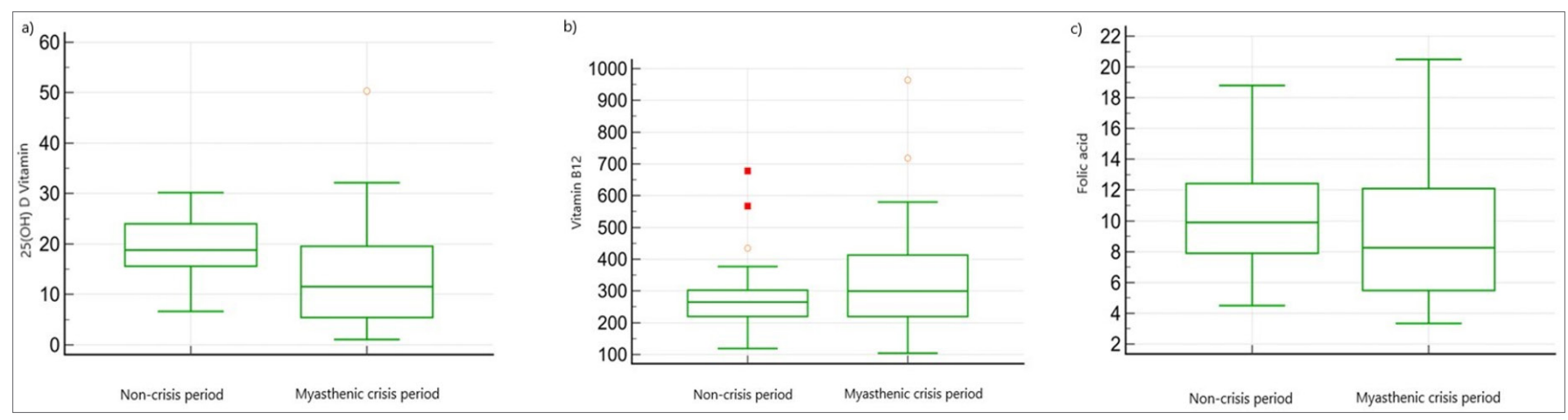

Figure 1. Serum vitamin D, vitamin B12, folic acid levels in myasthenic crisis and non-crisis periods 
worsening myasthenic symptoms and myasthenic crisis. We think that low serum $25(\mathrm{OH})$ vitamin D levels in patients with MG may have reduced the inhibitory effect of Treg cells on self-reactive $\mathrm{T}$ cells, leading to an increase in autoimmune response and aggravation of myasthenic symptoms. In this respect, we speculate that the use of VD supplements in MG patients with low VD levels may be beneficial in terms of protection from myasthenic crisis. We believe that large-scale studies on this subject will be more beneficial. According to our evaluation, this is the first study showing that VD levels are lower in the myasthenic crisis period than in the non-crisis period.

MG may be associated with autoimmune diseases such as SLE, rheumatoid arthritis and Hashimoto's thyroiditis at a rate of 5-10\% (17). The association of MG with pernicious anemia has also been reported very rarely $(18,19)$. Antiparietal cell and anti-intrinsic factor antibody positivity has been demonstrated in some MG patients $(20,21)$.

However, B vitamins also have direct regulatory effects on the immune response (22). In particular, vitamin B12 has been shown to play an important role by upregulating these cells for the cytotoxic immune response mediated by both natural killer cells and CD8 (+) T cells (23). In our study, no significant difference was observed between vitamin B12 levels in myasthenic crisis and noncrisis periods. While MG is primarily a CD4 (+) T celldependent disease, the fact that vitamin B12 is mostly involved in natural killer and CD8(+) T cell-dependent immunogenic functions, the rare association of MGpernicious anemia and the low number of patients in the study may have played a role in this result.

Folic acid deficiency has been associated with reduced maturation of dendritic cells (DC), lower secretion of IL-12, TNF- $\alpha$, IL- 6 and IL- $1 \beta$ by DCs, and impaired differentiation of $\mathrm{CD} 4(+) \mathrm{T}$ lymphocytes $(6,7)$. In addition, high-dose oral folic acid administration in mice with atopic dermatitis has been shown to reduce $\mathrm{T}$ cell proliferation and reduce the inflammatory response by suppressing the secretion of proinflammatory and Th2 cytokines (IL-4, IL-5, IL-9, IL-13, IL-17, IL-33) (8). Methotrexate, a structural analogue of folic acid, is an immunosuppressive drug that acts as an antimetabolite by selectively inhibiting the dihydrofolate reductase enzyme. There are conflicting results in studies on the efficacy of methotrexate in MG patients. In some studies, it has been stated that the use of methotrexate in MG patients leads to improvement in myasthenic symptoms or a decrease in corticosteroid requirement in $38-87 \%$ of patients. The mechanism by which methotrexate provides improvement over folic acid in MG patients was not mentioned in any of these studies $(24,25)$. Pasnoor et al. (26), in their randomized double-blind placebo- controlled study, reported that the use of methotrexate in MG patients did not reduce the dose of prednisolone needed and did not improve clinical MG scores.

The fact that no significant difference was observed in the folic acid levels of MG patients during the crisis and non-crisis periods in our study indirectly confirms the results of this study. Although our study was not primarily conducted on the pathophysiology of folic acid in MG patients, this result may indicate that the role of folic acid in the pathophysiology of MG may be limited. We believe that more extensive research on this subject will be beneficial.

\section{CONCLUSION}

In our study, VD levels were found to be significantly lower in the myasthenic crisis period than the non-crisis period. This result may indicate that low VD levels may be an important factor in worsening myasthenic symptoms and experiencing a myasthenic crisis. We speculate that the use of VD supplements in MG patients with low VD levels may be beneficial in preventing myasthenic crisis. There was no significant difference between vitamin B12 and folic acid levels between myasthenic crisis and noncrisis periods. Despite the limitations of our study, such as the small number of patients and the fact that $25(\mathrm{OH})$ D levels were not adjusted for seasonal effects, this study is the first study showing that VD levels are lower in the myasthenic crisis period than in the non-crisis period.

\section{ETHICAL DECLARATIONS}

Ethics Committee Approval: The study was carried out with the permission of Ethics Board of Atatürk University, Faculty of Medicine (Date: 06/33, Decision No: 30.09.2021).

Informed Consent: Written informed consent was obtained from all participants who participated in this study.

Referee Evaluation Process: Externally peer-reviewed. Conflict of Interest Statement: The authors have no conflicts of interest to declare.

Financial Disclosure: The authors declared that this study has received no financial support.

Author Contributions: All of the authors declare that they have all participated in the design, execution, and analysis of the paper, and that they have approved the final version.

\section{REFERENCES}

1. Rabinstein AA, Mueller-Kronast N. Risk of extubation failure in patients with myasthenic crisis. Neurocrit Care 2005; 3: 213 
2. Szodoray P, Nakken B, Gaal J, et al. The complex role of vitamin D in autoimmune diseases. Scand J Immunol 2008; 68: 261-9.

3. Holick M.F. Vitamin D deficiency. N Engl J Med 2007; 357: 26681.

4. Doğan $\mathrm{M}$, Doğan AG. Vitamin D yetersizliği ve eksikliğine güncel yaklaşım. J Health Sci Med 2019; 2: 58-61.

5. Depeint F, Bruce WR, Shangari N, Mehta R, O’Brien PJ. Mitochondrial function and toxicity: role of $\mathrm{B}$ vitamins on the one-carbon transfer pathways. Chem Biol Interact 2006; 163: $113-32$.

6. Elmadfa I, Meyer AL. The role of the status of selected micronutrients in shaping the immune function. Endocr Metab Immune Disord Drug Targets 2019; 19: 1100-15.

7. $\mathrm{Wu} \mathrm{CH}$, Huang TC, Lin BF. Folate deficiency affects dendritic cell function and subsequent $\mathrm{T}$ helper cell differentiation. J Nutr Biochem 2017; 41: 65-72.

8. Makino E, Fukuyama T, Watanabe Y, et al. Subacute oral administration of folic acid elicits anti-inflammatory response in a mouse model of allergic dermatitis. J Nutr Biochem 2019; 67: 14-9.

9. Aricha R, Feferman T, Scott HS, Souroujon MC, Berrih-Aknin S, Fuchs S. The susceptibility of Aire(-/-) mice to experimental myasthenia gravis involves alterations in regulatory $\mathrm{T}$ cells. J Autoimmun 2011; 36: 16-24.

10. Mok CC, Birmingham DJ, Ho LY, Hebert LA, Song H, Rovin BH. Vitamin $\mathrm{D}$ deficiency as marker for disease activity and damage in systemic lupus erythematosus: a comparison with anti-dsDNA and anti-C1q. Lupus 2012; 21:36-42.

11. Varenna M, Manara M, Cantatore FP, et al. Determinants and effects of vitamin D supplementation on serum 25-hydroxyvitamin D levels in patients with rheumatoid arthritis. Clin Exp Rheumatol 2012; 30: 714-9.

12. Smolders J, Menheere P, Kessels A, Damoiseaux J, Hupperts R. Association of vitamin D metabolite levels with relapse rate and disability in multiple sclerosis. Mult Scler 2008; 14: 1220-4.

13. Dügeroğlu H. Evaluation of 25-hydroxy vitamin D levels in COVID- 19 positive patients J Health Sci Med 2021; 4: 931-5.

14. Kang SY, Kang JH, Choi JC, Song SK, Oh JH. Low serum vitamin D levels in patients with myasthenia gravis. J Clin Neurosci 2018; 50: 294-7.

15. Justo ME, Aldecoa M, Cela E, et al. Low vitamin D serum levels in a cohort of myasthenia gravis patients in Argentina. Photochem Photobiol 2021; 10.1111/php.13432. doi:10.1111/php.13432

16. Askmark H, Haggård L, Nygren I, Punga AR. Vitamin D deficiency in patients with myasthenia gravis and improvement of fatigue after supplementation of vitamin D3: a pilot study. Eur J Neurol 2012; 19: 1554-60.

17. Richman DP, Agius MA. Acquired myasthenia gravis: immunopathology. Neurol Clin 1994; 12: 273-84.

18. Chang KH, Lyu RK, Ro LS, Wu YR, Chen CM. Coexistence of pernicious anemia and myasthenia gravis--a rare combination of autoimmune diseases in Taiwan. J Formos Med Assoc 2006;105: 946-9.

19. Khademolhosseini S, Springsted E, Pourshahid S, Giri B. Coexistence of pernicious anemia and myasthenia gravis presenting as dyspnea. Cureus 2021; 13: e15295.

20. Krol TC. Myasthenia gravis, pernicious anemia, and Hashimoto's thyroiditis. Arch Neurol 1979; 36: 594-5.

21. Zittoun J, Tulliez M, Estournet B, Goulon M. Humoral and cellular immunity to intrinsic factor in myasthenia gravis. Scand J Haematol 1979; 23: 442-8.

22. Wintergerst ES, Maggini S, Hornig DH. Contribution of selected vitamins and trace elements to immune function. Ann Nutr Metab 2007; 51: 301-23.
23. Tamura J, Kubota K, Murakami H, et al. Immunomodulation by vitamin B12: augmentation of CD8+ T lymphocytes and natural killer (NK) cell activity in vitamin B12-deficient patients by methyl-B12 treatment. Clin Exp Immunol 1999; 116: 28-32.

24. 24.Hartmann J, Rivner MH. Methotrexate in myasthenia gravis. Clin Neurophysiol 2009; 120: e123-e124.

25. Koźmiński P, Halik PK, Chesori R, Gniazdowska E. Overview of dual-acting drug methotrexate in different neurological diseases, autoimmune pathologies and cancers. Int J Mol Sci 2020; 21: 3483.

26. Pasnoor M, He J, Herbelin L, et al. A randomized controlled trial of methotrexate for patients with generalized myasthenia gravis. Neurology 2016; 87: 57-64. 